\title{
Infections Related to Health Care in Newborns: Documental Study Based on Analysis of Research Database
}

\author{
Lucas Lima de Carvalho $^{1}$ (i), Lucas Rodrigues Claro' ${ }^{(1)}$, Amanda dos Santos Cabral ${ }^{1}$ (i),

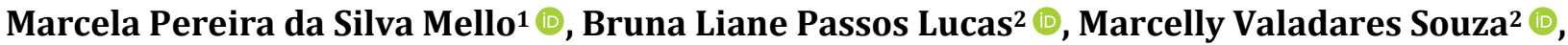 \\ Simone Fonseca Lucas ${ }^{3}$ (D), Alexandre Oliveira Tellles ${ }^{4}$ (i), \\ Ravini Fernandez dos Santos Vieira dos Santos ${ }^{5}$ (), Marcia Augusta Pereira dos Santos ${ }^{4}$ (), \\ Claudia Lima Campos Alzuguir ${ }^{4}\left(\mathbb{D}\right.$, Maria Cristina Dias da Silva ${ }^{4}(\mathbb{D}$, \\ Antonio Eduardo Vieira dos Santos ${ }^{6}$ (D), Maria Antonieta Rubio Tyrrell1 ${ }^{(1)}$, \\ Eduardo Alexander Júlio César Fonseca Lucas4 4
}

\footnotetext{
${ }^{1}$ Anna Nery School of Nursing, Federal University of Rio de Janeiro, Rio de Janeiro, Brazil

${ }^{2}$ Celso Lisboa University Center, Rio de Janeiro, Brazil

${ }^{3}$ State Secretariat of Education of Rio de Janeiro, Rio de Janeiro, Brazil

${ }^{4}$ Department of Medicine in Primary Health Care, Faculty of Medicine, Federal University of Rio de Janeiro, Rio de Janeiro, Brazil ${ }^{5}$ Department of Maternal and Child Nursing, Faculty of Nursing, State University of Rio de Janeiro, Rio de Janeiro, Brazil

${ }^{6}$ Department of Maternal-Child Nursing, Faculty of Nursing, Fernandez Figueira Institute of the Oswaldo Cruz Foundation, State University of Rio de Janeiro, Rio de Janeiro, Brazil

Email: eduardoalexander@medicina.ufrj.br
}

How to cite this paper: de Carvalho, L.L., Claro, L.R., dos Santos Cabral, A., da Silva Mello, M.P., Lucas, B.L.P., Souza, M.V., Lucas, S.F., Tellles, A.O., dos Santos Vieira dos Santos, R.F., dos Santos, M.A.P., Alzuguir, C.L.C., da Silva, M.C.D., dos Santos, A.E.V., Tyrrell, M.A.R. and Lucas, E.A.J.C.F. (2020) Infections Related to Health Care in Newborns: Documental Study Based on Analysis of Research Database. Health, 12, 1360-1370. https://doi.org/10.4236/health.2020.1210097

Received: September 25, 2020

Accepted: October 24, 2020

Published: October 27, 2020

\begin{abstract}
This documentary research aimed to describe the results of an epidemiological survey that sought to determine the prevalence of Infections Related to Health Care (IRHC) in newborns admitted to a Neonatal Intensive Care Unit (NICU) at the city of Rio de Janeiro. For methodology, the existing data in the original research database were used as the primary source. The method used was the case study in a quantitative approach. The data have been statistically arranged by odds ratio, which measured the possibility of IRHC development at the 102 newborns, by exposition at the risk factors. Results: IRHC prevalence with pneumonias, sepsis, navel's infection and ocular infections predominance rises. Prematures are 4.10 more susceptible. Twelve hours after amniotic rupture there are 1.77 more chances of infections. Babies with more than 10 days of hospitalization are 4.70 more susceptible than those with 10 days. The registers examined were incipient at the IRHC's characterization, beginning and duration, which make the IRHC's diagnos-
\end{abstract}


Copyright (อ 2020 by author(s) and Scientific Research Publishing Inc. This work is licensed under the Creative Commons Attribution International License (CC BY 4.0).

http://creativecommons.org/licenses/by/4.0/ tic/notification difficult.

\section{Keywords}

Neonatal Nursing, Cross Infection, Data Interpretation, Statistical

\section{Introduction}

Hospital Infection (HI) or Infection Related to Health Care (IRHC) is one of the biggest problems in healthcare sectors worldwide. It affects people of the most diverse characteristics, whether white or black, adults or children, rich or poor. However, it is known that certain factors can make some groups more susceptible, where we can highlight as an example, poverty, which imposes conditions that are often not consistent with a standard of living necessary to maintain health. This does not take into account that people from less privileged social classes do not always have the means to access quality health services.

The emergence of IRHC occurs with hospitalization and its manifestation occurs during or after the client leaves the hospital, and may have an endogenous or exogenous origin. Infections of endogenous origin are associated with underlying disease or conditions, where microorganisms in the patient's own flora are responsible for most IRHC. In this case, prevention is limited. Exogenous infections, on the other hand, are related to the invasive diagnostic and/or therapeutic procedures performed, constituting a risk, which, however, when circumvented, can prevent IRHC. The problem of HI in Brazil is growing, considering the high cost of medical care that can be up to three times higher than the cost of patients without infection. The epidemiological data available show that the rates of IRHC remain high, $15.5 \%$, which corresponds to 1.18 episodes of infection per client hospitalized with IRHC in Brazilian hospitals [1].

In principle, erroneously, it is thought that infections that occur in the newborn unit are occasional, relatively small and easy to control. However, when studying the issue of IRHC in neonatal units, one must take into account the peculiarities of this type of clientele; given that newborns (NB's) have an immaturity of the immune system, which in itself already represents a predisposing factor. This is without considering that in Neonatal Intensive Care Units (NICUs) the type and amount of therapeutic and diagnostic invasions carried out are varied and numerous, which correlatively, increase the risk of IRHC. So much so, those studies carried out by Mesquita et al. about the epidemiological profile of newborns who acquired hospital infection in 2009 in a Neonatal Intensive Care unit revealed the magnitude of IRHC in tertiary hospitals, indicating that the NICU is the hospital unit that presents the higher prevalence of IRHC [2]. 


\subsection{Objective}

Discuss aspects related to the prevalence of IRHC in newborns admitted to a Neonatal Intensive Care Unit (NICU) in the city of Rio de Janeiro, based on the results of a field research database carried out from January to July 1997.

\subsection{Importance of the Study}

The present study has its value since, despite the efforts being made by the Hospital Infection Control Commissions (HICC), the number of clients subject to IRHC is significant. In addition, infections can often not even appear as a given in newsletters, thus characterizing underreporting. Concerned about this issue, THOMAZ points out that: The creation of an information system in which health professionals or anyone can and should notify health authorities about the existence of diseases that pose a threat to public health, dates back many years. So that immediate actions can be taken in view of the knowledge of the health situation of the Brazilian population [3].

However, it is known that the reality has been a little different, where in hospital institutions many cases of IRHC are not reported. Therefore, it is possible to point out as causes of this under-registration: the diagnostic uncertainty itself; operational issues, illustrated by the lack of an appropriate form or the "lack of time" of professionals for bureaucratic procedures; and mainly the indifference resulting from the disbelief in the Epidemiological Surveillance (ES) system [3]. As a result, a vicious circle of discouraging staff and poor quality of information from ES is formed in many health care centers. Part of the blame, at the service level, is usually attributed to the professionals, who should notify or properly record the data in medical records or certificates, but they do not do so. Many professionals believe that the notification serves as an input to supply a database with no practical use, since nothing happens after registration, except the production of statistics and lags [3].

Thus, it is necessary to raise health professionals' awareness of these issues, as well as the best professional training, and especially the provision of favorable working conditions. Such requirements represent important strategies on the way to improving the health information system. So, it is hoped that this study can somehow give a better visibility of the phenomenon, in order to answer the questions that arose from the authors' daily routine in the practice scenarios in which they work.

\section{Method}

\subsection{Kind of Study}

This work consisted of a documentary research that used as a database an epidemiological survey, of a descriptive nature, in which we sought to gather information about the distribution of an event, which in this case, were hospital infections in newborns. 


\subsection{Nature of the Study}

A quantitative approach was used in which Lakatos, Gil and Minayo [4] [5] [6] point out that the quantitative method can explain social reality through objectivity. Nevertheless, in line with the statements of this same author, this research brought up qualitative elements, to strengthen the analysis, attributing relationships and meanings, during the contextualization of the data collected.

\subsection{Universe}

The universe of this research was represented by the information available in the research database that investigated, in 1997, neonates admitted to the NICU.

\subsection{Sample}

This work had as a sample the information stored in the database related to 102 NBs hospitalized in the NICU between the period from January 1 to July 31, 1997, considering the accessibility criteria that characterize a non-probabilistic type of sampling.

\subsection{Research Field}

The research field of the research that originated the information stored in the database for this investigation, was composed of a NICU linked to a Federal Higher Education Institution (FHEI). This is because, since this field is linked to a higher education institution, and integrated assistance, teaching and research activities are developed there, it was believed, then, that this place could, at the time, better represent the health model more compatible with established by the Ministry of Health standards.

\subsection{Chosen Method}

We opted for the case study method, seeking to associate some risk factors to neonatal infections, since according to PEREIRA [7]. The case study constitutes a true inventory of what happens generically, in the light of observation few individuals.

\subsection{Study Object}

Based on information in a research database, IRHC in neonates was established as the object of this study, where they are associated with three main elements: the hospital, the group of people who care, and the group of people that is taken care of: the newborns. Of these, it was discussed more openly about NB's and the nursing team, since it is responsible for an expressive variety of care provided to clients.

\subsection{Data Collection Procedures and Technique}

The data source of the present research was the database of the study entitled: "Hospital Infections and the Problem of Underreporting: two questions for ref- 
lection on the daily nursing professional". The following information from the newborns was extracted from this database, based on a script: type of childbirth, length of hospital stay, among others. These variables were selected in the present study, because according to the scientific literature available on the topic, they represent important risk factors for IRHC's in newborns admitted to NICU [8]. The script was previously prepared, meeting the basic questions of descriptive epidemiology. It should be noted that the original research met all ethical considerations for research involving human beings by complying with the recommendations of Resolution $\mathrm{N}^{\circ} 196$ of 1996 of the National Health Council, which at the time of the research established criteria for preserving secrecy, confidentiality and total and complete anonymity of the study participants. The elaboration of the database was carried out in October 1997. During the data collection, quantitative information was captured, by consulting the medical records and nosological file of the 102 newborns.

\subsection{Data Processing}

After obtaining the data, they were treated using the statistical method and presented in absolute values and percentages of the epidemiological indicators found, being analyzed by the odds ratio method and degrees of significance, and then analyzed in the light of the concepts in the relevant bibliography. The odd ratio represented by the formula: $O R=(a \times d):(b \times c)$, where: $a \geq$ number of people exposed, or who had characteristics, and became ill; $b \geq$ number of exposed people who remained healthy; $c \geq$ number of unexposed people who became ill; $d \geq$ number of unexposed, healthy people.

\section{Presentation of Data}

Table 1 and Figure 1 and Figure 2 present the data using the odds ratio method, measuring the risk of neonates developing, in the field under study, IRHC from the following exposure factors: gestational age, type of delivery, time of rupture of the membranes and time hospitalization of newborns.

From Figure 1, there is a predominance of pneumonia (21 cases), followed by bacterial septicemia (16), omphalitis (13), conjunctivitis (08), among other less frequent cases such as: impetigo (02 cases), undefined sepsis (05), moniliasis (05), necrotizing enterocolitis (02), hepatitis (01), gastroenteritis (01), and urinary tract infections (01). It is also noticed the occurrence of infections resulting from congenital transmission, such as syphilis (02) and TORCH (toxoplasmosis, rubella and cytomegalovirus and others) (01 case). The great difficulty faced by this investigation was to characterize the cases as infections related to health care in the newborns surveyed. This is because the primary sources consulted did not classify, in most cases, the registered infections, according to the criteria contained in the specific literature. With regard to determining the type of agent that causes infections, it is not possible to carry it out in the selected sample, 
Table 1. Distribution of newborns with and without infection, according to gestational age, type of childbirth, time of rupture of the amniotic sac and length of hospital stay. Source: research data-base.

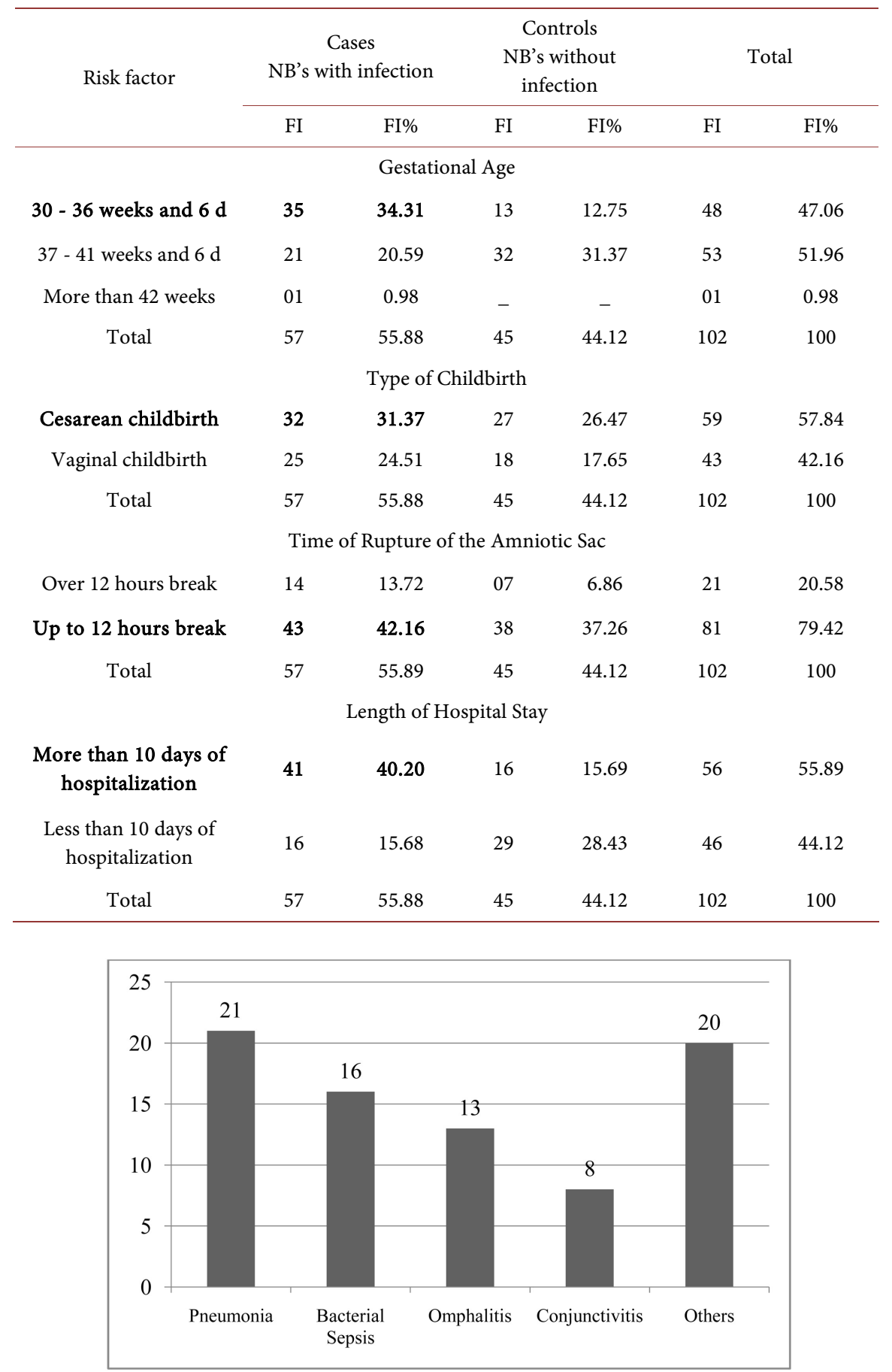

Figure 1. Distribution by type of infections among the $57 \mathrm{NBs}$ infected during the period of stay in the NICU (January to July/Brazil, 1997) Source: Research data-base.

because there were almost always no laboratory results that could accurately guide the diagnosis and treatment of infections (such as blood culture and the 


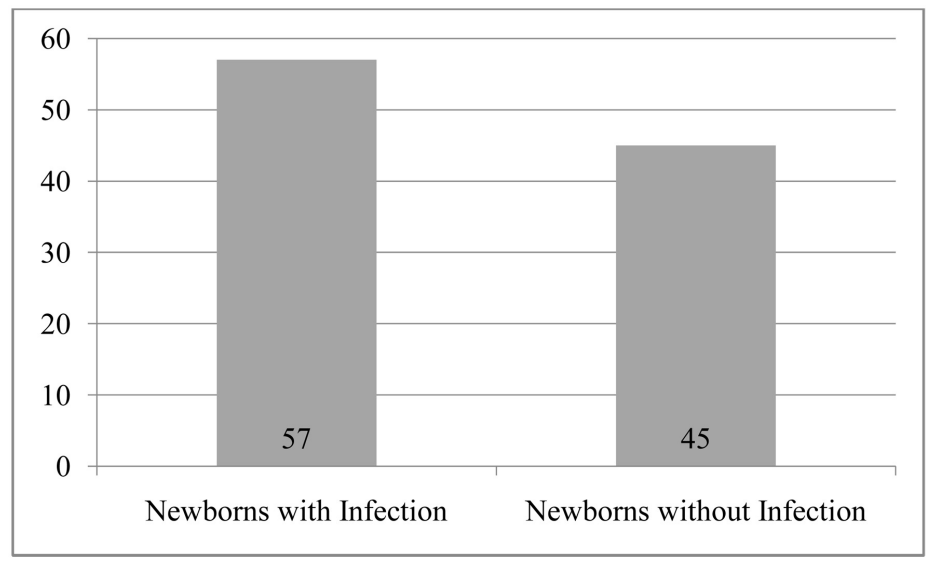

Figure 2. Distribution of the prevalence of infections among the 102 clients admitted to the NICU (January to July/Brazil, 1997). Source: Research data-base.

antibiogram). Paying attention to this situation, based on the statements of, it is necessary to emphasize the importance of standardization and control of the prescription of antibiotics based on cultures and sensitivity coefficients of microorganisms to antimicrobials [9].

According to the data exposed by Figure 2, there is a high prevalence of infections in NBs admitted to the NICU. This finding is perfectly explainable in the light of the available literature, where several authors point out that the specificities of the newborn's immune response due to the aggression of infectious agents generally result in decreased resistance. Thus, it seems that this high prevalence of infections in the 102 newborns studied, is associated with such conditions then pointed out. Also, attention should be paid to the causes that concern exogenous factors, and that certainly contribute to the increase in the occurrence of neonatal infections. Hence the importance of measures for the prevention and control of IRHC to minimize the diagnostic situation found [10] [11].

The measure of the odds ratio showed that premature NBs admitted to the NICU are 4.10 times more likely to be infected than full-term NBs. This greater susceptibility can be attributed to the fact that prematurity further accentuates the immaturity of the immune system of these babies. Measuring the risk of these 102 children presenting infection, using the odds ratio, it appears that neonates born by cesarean childbirth contracted less infection than those born by vaginal childbirth $(\mathrm{OR}=0.85)$. The childbirth weight variable could not be studied, given its absence in the nosological records of the researched scenario.

The results reveal a low risk for cesarean sections. However, according to PEREIRA $^{7}$, practically, in any investigation, there will be the "exposed" who remain "healthy" and the "unexposed" who become "sick". Furthermore, despite efforts by the Ministry of Health, there is still a high percentage of operative deliveries, indicating the need for further studies to further analyze this situation, especially with regard to maternal and child morbidity and mortality due to cesarean sections [12] [13]. 
Concerned with the problem of amniotic infection, Rezende and Montenegro [14] warn that the amniotic fluid alkalizes the vagina creating conditions conducive to the development of germs responsible for the ascending infection of the ovular cavity. The calculation of the odds ratio revealed that children admitted to the NICU, born after $12 \mathrm{~h}$ after the rupture of the amniotic sac, are 1.77 times more likely to present infection, compared to children who were born within 12 $h$ of the ruptured sac.

It can be seen that the odds ratio of children with more than 10 days of hospitalization in the NICU are 4.7 times more likely to develop infection, compared to those who have been hospitalized for up to 10 days.

\section{Discussion}

Nowadays, there are not a few scholars concerned with the topic of IRHC. Such interest stems from numerous factors, among which can be considered: the magnitude and the increasing manifestation of IRHC as a health problem in the world population; the increase in the cost of hospital and family care; the occurrence of multidrug-resistant strains to the latest generation of antibiotics, among others.

With regard to infections that affect children in the neonatal period, given the uniqueness of this type of clientele, it is a consensus in neonatology, that infections are still one of the main causes of morbidity and mortality in this period, generating deleterious consequences on the lives of (NBs) and your family. Regarding the data obtained, this investigation had difficulty in determining the prevalence in the researched scenario.

This is because the sources available in the service did not, in most cases, classify the infections registered according to the criteria contained in the programmatic bases and specific literatures, as well as they did not explain the starting date of the infectious process. In addition, there was no bacteriology service at the research institution, thus determining the absence of extremely important information, such as blood culture results. For this reason, it has become impossible to determine the type of agent causing infections in NBs with precision, thus making it difficult to characterize infections in the NICU.

After some adjustments, we finally arrived at the following results: high prevalence $(56 \%)$ of neonatal infections in the period from January to July 1997, with a predominance of pneumonias, bacterial septicemias, omphalitis, followed by others. The emerging qualitative data revealed that some professionals are unaware of the importance of recording IRHC notification.

As for the nature of the records, it was observed that these were, in general, incipient with regard to the characterization of infectious processes. This was attributed to the interference of the human component, since the clarity/precision of the information contained in the medical records varied according to the professional who performed it. Regarding the nosological file, it could be organized in a way that allows the specification of the causal agent of infections, for 
better characterization of infections in the NICU, and thus to optimize their notification, since the data presented demonstrate the underreported cases of IRHC. It is also worth mentioning that one (HICC) was not identified in the studied scenario, in disagreement with the legal and political guidelines of the Ministry of Health, in the fight against IRHC (Ordinance $\mathrm{N}^{\circ} 2616$ of May 12, 1998 [15] that provides for the current policy of prevention and control of IRHC in the country's health services). For health professionals, these data should serve as an indication of the need for reflection on the professional routine. This is because, the area of health as an art and science comprises a scope of human knowledge that enables individuals, groups and collectivities to promote, maintain and recover health. To this end, it is necessary that professionals are attentive to the provision of effectively qualified assistance and without iatrogenies based on public policies related to the prevention and control of these infections [16] [17].

It is worth highlighting briefly that among the main ways of preventing IRHC's in NICU we should be: 1) comply the precautions for contact with newborns; 2) hand hygiene following the correct technique, using antiseptic solutions or $70 \%$ alcohol; 3) avoid a high occupancy rate and pay attention to the number of patients by health professionals; 4) reduce the risk of contamination of the catheter by adhering to the standards established by the HICC; 5) continuously educate the entire multidisciplinary health team and the newborn's companion admitted to the NICU; 6) monitor NICU infection rates through proper registration in the newborns' medical record, as well as notification of IRHC's cases to HICC and competent authorities; 7) promote the rational and discerning use of antimicrobials; 8) qualify prenatal care to improve parturition and birth conditions; 9) reduce unnecessary invasive diagnostic and therapeutic procedures by adopting well-defined clinical protocols [8].

\section{Conclusions}

In relation to neonatal IRHC and the problem of underreporting, it is necessary that nursing, through its social commitment, increasingly strengthens its alliance with the assisted clientele, mobilizing itself so that fewer and fewer children admitted to NICUs are affected by infections, and that in their occurrence they are properly informed to the authorities through the institution's IHCC. We recommend to the research field reformulations in its information system, to optimize/favor the notification of IRHC in the NICU, in spite of the need to improve infrastructure at the institution, with the inclusion of a bacteriology service, as well as the creation of a permanent interdisciplinary commission for the control of nosocomial infection.

It is pertinent to highlight that the study of this problem was gratifying, as it allowed the authors to expand their knowledge of IRHC. We recognize the need to exhaust the issues raised here, through further studies, given the complexity of the theme. In addition, it is worth noting that the information recorded in this data in the survey shows, from the results presented, that hospital infections 
have long been a global public health problem, therefore deserving a close look from government officials, managers, health professionals, as well teaching and research institutions around the world. The data from the present research reveal that all the variables analyzed demonstrated an impact on the occurrence of IRHC's. However, the length of hospital stay and time of rupture of the amniotic sac increased the risk of infection in newborns admitted to NICU more significantly, with odds ratio of 4.7 and 1.77, respectively.

\section{Conflicts of Interest}

The authors declare no conflicts of interest regarding the publication of this paper.

\section{References}

[1] Sousa, A.F.L., Oliveira, L.B. and Moura, M.E.B. (2016) Perfil epidemiológico das infecções hospitalares causadas por procedimentos invasivos em unidade de terapia intensiva. Revista Prevenção de Infecção e Saúde, 2, 11-17.

https://doi.org/10.26694/repis.v2i1-2.6048

[2] Mesquita, K.O., Almeida, E.C.B., Lima, G.K., Dias, I.C.X., Silva, V. and Linhares, M.S.C. (2010) Perfil Epidemiológico das Infecções Hospitalares na UTI Neonatal da Santa Casa de Misericórdia de Sobral no ano de 2009. SANARE Revista de Políticas Públicas, Sobral, 9, 66-72.

[3] Thomaz, É.B.A.F., Pinho, J.R.O., Abreu, T.Q. and Rodrigues, V.P. (2015) Conceitos e ferramentas da epidemiologia/Judith Rafaelle Oliveira Pinho (Org.). Universidade Federal do Maranhão. UNA-SUS/UFMA. EDUFMA, São Luís.

[4] Lakatos, E.M. and Marconi, M.A. (2003) Fundamentos de metodologia científica. 5th Edition, Atlas, São Paulo.

[5] Gil, A.C. (2007) Como Elaborar Projetos de Pesquisa. 4th Edition, [10a Reimp]. Atlas, São Paulo.

[6] Minayo, M.C.S. (2004) O desafio do conhecimento: Pesquisa qualitativa em saúde. 8th Edition, Hucitec, São Paulo, Rio de Janeiro.

[7] Pereira, M.G. (1995) Vigilância Epidemiológica. In: Epidemiologia: Teoria e Prática, Guanabara Koogan, Rio de Janeiro, Cap. 21, 449-479.

[8] Pinheiro, M.S.B. (2008) Epidemiologia da infecção hospitalar e mortalidade intrahospitalar de uma unidade de terapia intensiva neonatal em hospital de referência regional de São Paulo. Dissertation, University of São Paulo, Faculdade de Medicina, São Paulo. https://doi.org/10.11606/D.5.2008.tde-29012009-113032

[9] Couto, R.C., Pedrosa, T.M.G. and Nogueira, J.M. (2003) Infecção Hospitalar e outras Complicações Não-infecciosas da Doença. 3a Edição.

[10] Behrman, R.E., Kliegman, R. and Jenson, H.B. (2017) Nelson. Tratado de Pediatria. 20th Edição, Vol. 1 e 2, Guanabara Koogan, Rio de Janeiro.

[11] Marcondes, E. and Alcântara, P. (1994) Infecções. In: Pediatria Básica, Sarvier, São Paulo, Volume 2, seção II, 1597-1613.

[12] Cardoso, P.O., Alberti, L.R. and Petroianu, A. (2010) Morbidade neonatal e maternas relacionada ao tipo de parto. Ciência \& Saúde Coletiva, Rio de Janeiro, 15, 427-435. http://www.scielo.br/scielo.php?script=sci_arttext\&pid=S1413-81232010000200019 $\underline{\text { \&lng }=\text { en\&nrm }=\text { iso }}$ 
https://doi.org/10.1590/S1413-81232010000200019

[13] Rodrigues, C.S., et al. (1997) Perfil dos nascidos vivos no município de Belo Horizonte, 1992-1994. Cadernos de Saúde Pública, 13, 53-57.

https://doi.org/10.1590/S0102-311X1997000100014

[14] Rezende, J. and Montenegro, C.A.B. (2018) Doenças infecciosas. Obstetrícia Fundamental. 14th Edition, Guanabara Koogan, Rio de Janeiro.

[15] Brasil, Ministério da Saúde (1998) Portaria No. 2616. Diário Oficial da União. Brasília, 12 de maio de.

[16] Brasil, Ministério da Saúde (1995) Avaliação da Qualidade das Ações de Controle Hospitalar em Hospitais Terciários. Revista do Controle de Infecção Hospitalar, Brasília, 1, 32-33.

[17] Brasil, Ministério da Saúde (1994) Secretaria de Assistência à Saúde, Coordenação Materno-Infantil. Profilaxia e Controle das Infecções Neonatais. Manual de Assistência ao RN. Brasília. CAP XIII, 127-130. 